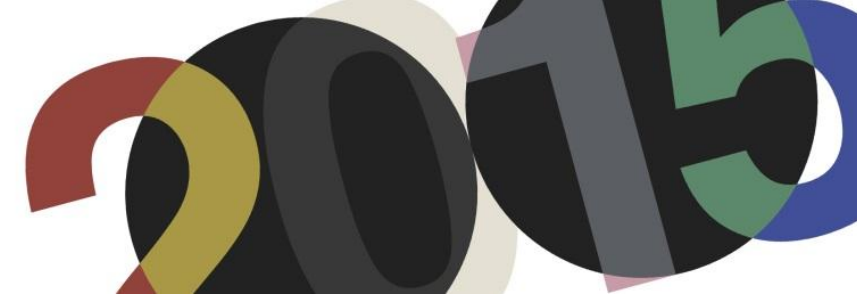

DOI: http://dx.doi.org/10.4995/LC2015.2015.699

\title{
Captando la mirada. Publicidad y reclamo en el espacio expositivo de Le Corbusier
}

\author{
J. Granados González \\ Universidad Católica de Murcia UCAM
}

\begin{abstract}
Resumen: Dentro de la obra de Le Corbusier, el espacio expositivo fue un tema ampliamente desarrollado. La idea de generar un prototipo teórico de museo, por ejemplo, fue recurrente a lo largo de toda su obra, como una idea latente, en gestación, a la espera del momento para ser llevada a la realidad de la construcción. En el caso concreto del museo de crecimiento ilimitado, desarrollado teóricamente a lo largo de la década de 1930, los pocos ejemplos construidos son ejecutados a partir de los años cincuenta. Al realizar una compilación de los ejemplos de espacios expositivos proyectados por Le Corbusier, siguiendo líneas tipológicas similares, en donde se incluyan no solo museos, sino también, pabellones y salas de exposición, montajes expositivos e, incluso, propuestas comerciales (donde lo expuesto es una mercancía), se constata que el número total de obras supera las ochenta, abarcando proyectos desde 1910 (la sala de exposiciones del Taller de artistas) hasta la muerte de Le Corbusier en 1965, con el último ejemplo proyectado: el museo del siglo XX en Nanterre. A la hora de analizar las distintas estrategias proyectuales empleadas por el maestro a la hora de enfocar la arquitectura expositiva, un punto interesante es el reclamo publicitario, la propaganda y la captación del interés de los visitantes, la relación con el diseño gráfico y la publicidad, el empleo del color, el grafismo o la cartelería. Todos estos aspectos son especialmente relevantes en el caso de pabellones de exposición y pabellones para marcas comerciales.
\end{abstract}

Abstract: Within the work of Le Corbusier, the exhibition space was a theme widely developed. For example, the idea of a theoretical prototype of the museum was recurrent throughout his work, as a latent idea, waiting for the time to be taken to the reality of construction. In the case of the museum of unlimited growth, theoretically developed throughout the 1930s, the few built examples are executed from the fifties. In carrying out a compilation of examples of exhibition spaces designed by Le Corbusier, following similar typological lines, where not only museums but also pavilions, exhibition halls, expositions and even commercial proposals are included, we find that the total number of works exceeds eighty, covering projects since 1910 (the exhibition hall of the Ateliers d'Artistes) to the death of Le Corbusier in 1965, with the final example: the Museum of the 20th Century in Nanterre. When analyzing the different design strategies employed by the Master at the exhibition architecture, an interesting point is the study of advertising, propaganda (attracting the interest of visitors), the relationship with graphic design, and the use of color, graphics and signage. All these aspects are especially relevant in the case of exhibition halls and pavilions for trademarks.

Palabras clave: pabellones; exposiciones; museos; publicidad.

Keywords: pavilions; exhibitions; museums; advertising.

\section{Introducción}

Antes de analizar los sistemas publicitarios aplicados a la arquitectura expositiva de Le Corbusier, parece apropiado contextualizar este nuevo medio de expresión artística desarrollado dentro de la cultura visual de masas.

Los avances tecnológicos que surgieron a partir de la Revolución Industrial transformaron la sociedad del siglo XIX. Los procesos industriales alentaron la producción y, en consecuencia, el consumo, siendo la competencia uno de los elementos más destacados del nuevo mercado, y el reclamo publicitario la herramienta más explotada para la atracción del consumidor. El carácter interdisciplinar de la publicidad se muestra en los numerosos 
campos a los que recurre, como la fotografía, la tipografía, el dibujo o el diseño gráfico, y en general el mundo de la imagen.

La evolución de la publicidad va ligada al desarrollo de los sistemas de reproducción masiva y a los medios de difusión. En un primer momento, y gracias a los avances en el campo de la litografía, el cartel fue el primer recurso publicitario que supera la mera finalidad práctica para experimentar con los medios plásticos. Eslabones de este proceso pueden ser las figuras de Jules Chéret (1836-1932), Alphonse Mucha (1860-1930), Henri de Toulouse-Lautrec (1864-1901) y Aubrey Beardsley (1872-1898). Su desarrollo en las primeras décadas del siglo XX viene marcado por el carácter experimental de las vanguardias, especialmente los proyectos propagandísticos promovidos tras la Revolución Rusa, con artistas tan destacados como El Lissitzky (18901941) o Aleksandr Ródchenko (1891-1956); así como, el aspecto más decorativo promovido por el Art Déco, ejemplificado en la figura de Cassandre (1901-1968).

La importancia que adquirió la disciplina se muestra claramente en los programas docentes de la Bauhaus ${ }^{1}$, donde la publicidad era uno de los cinco campos en que se dividía el "segundo nivel" o "enseñanza principal". En 1919 aparecía vinculada al Taller de imprenta, todavía enfocado como un trabajo artesanal, dirigido por Lyonel Feininger (1871-1956), al que sustituyó Herbert Bayer (1900-1985) en 1925, dando una mayor importancia a la tipografía y la propaganda. A partir de 1928, se hizo cargo del mismo Joost Schmidt (18931948), ya bajo el nombre de Sección de tipografía y publicidad.

Como muestra del momento de exaltación de este nuevo medio de comunicación de masas, se pueden citar las palabras del escritor Blaise Cendrars (1887-1961), "La publicidad es la flor de la vida contemporánea; es una afirmación de optimismo y alegría [...].Sin duda, la publicidad es la más bella expresión de nuestra época, la mayor novedad actual, todo un arte. Un arte que recurre al internacionalismo, o poliglotismo, a la psicología de masas, y que revoluciona todas las técnicas estáticas o dinámicas conocidas al utilizar, de forma intensiva, continua y eficaz, materias nuevas y procedimientos inéditos",2.

\section{La arquitectura expositiva como arquitectura publicitaria}

El empleo arquitectónico de los recursos publicitarios tiene su ejemplo más claro en la arquitectura de ferias y muestras internacionales, así como en el desarrollo de la arquitectura corporativa y marcas comerciales. En palabras de Moisés Puente: “Como los puestos de los charlatanes, lo importante es hacerse notar, atraer al espectador hacia aquello que se anuncia. El 'pasen-y-vean' ya no se vocea, es la propia arquitectura la que se encarga de hacerlo. El pabellón de exposiciones se carga de toda la iconografía derivada de la arquitectura publicitaria: colores, luces, neones, grandes rótulos, banderolas, logotipos, marquesinas-anuncio en un ambiente festivo por competir por la atención de los visitantes ${ }^{3 "}$.

Analizando la evolución de la arquitectura expositiva desde el punto de vista del uso de los recursos arquitectónicos como medio de propaganda y publicidad, se pueden establecer cuatro etapas bien diferenciadas. En una primera fase, el prototipo elegido fue el recinto expositivo o pabellón vitrina, ejemplificado en el Crystal Palace de Joseph Paxton, levantado con motivo de la Great Exhibition of the Works of Industry of all nations,

\footnotetext{
${ }^{1}$ Wick, Rainer: La pedagogía de la Bauhaus. Madrid: Alianza Editorial, 2007.

${ }^{2}$ Cendrars, Blaise: "Publicité = Poésie". En Aujourd'hui. Paris, 26 de febrero 1927.

${ }^{3}$ Puente, Moisés: Pabellones de exposición. 100 años. Barcelona: Editorial Gustavo Gili, 2000. p. 10.
} 
celebrada en Londres (1851). Un gran contenedor acogía en su interior un vasto espacio donde se disponían los distintos artilugios, y donde pequeños stands, a la manera de vitrinas expositivas, se destinaban a inventos de grandes empresas o a productos nacionales. Como si de un gabinete de curiosidades se tratara, los elementos expuestos se yuxtaponen sin solución de continuidad.

Se puede reconocer una segunda fase cuando se empiezan a diversificar los espacios expositivos, generando distintos pabellones $\mathrm{y}$, especialmente, desde el momento en el que se comienzan a levantar espacios representativos de las diferentes nacionalidades. La imagen exterior que cada Estado quiere transmitir en las muestras internacionales se asociará, en muchos casos, con la tradición, los tópicos e, incluso, el exotismo, recurriendo al empleo del historicismo y el eclecticismo, donde los estilos arquitectónicos del pasado se reinterpretan como manifestaciones de esa pretendida identidad sociocultural. Los históricos estilos nacionales, sobre todo los más extravagantes, se convirtieron en reclamo para el público, ávido de novedades.

Un tercer estadio puede ser identificado con la irrupción de la modernidad. La consolidación del Estilo Internacional llevará aparejada, en gran medida, la uniformidad en la imagen exterior de los edificios. Volúmenes prismáticos, formas rotundas, grandes superficies acristaladas, supresión de elementos decorativos y su característico color blanco exterior, definirán esta nueva imagen que rechaza cualquier identidad geográfica o social, como muy bien se puso de manifiesto en la Exposición Internacional de Arquitectura Moderna, celebrada en el MOMA de Nueva York en 1932.

Ante esta nueva arquitectura, despojada de historicismos, se hizo necesario el apoyo de diferentes recursos arquitectónicos, diseño gráfico, publicidad, tipografía, eslóganes, montajes fotográficos, banderolas, piezas artísticas, etc., para llamar la atención del visitante y desplegar todo un discurso propagandístico. Con esto no quiere decirse que anteriormente no habían sido utilizadas banderas, carteles, tipografía u otros recursos publicitarios, si no que es, a partir de este momento, cuando su uso se hace indispensable y especialmente destacable, cuando la arquitectura engloba en su diseño estos elementos, sin quedar constituidos como meros añadidos. En este sentido son significativas las palabras de Moholy-Nagy: "El concepto de 'fachada' ha sido eliminado de la arquitectura. Ya no hay lugar del edificio que no sea aprovechado con un propósito funcional. El aprovechamiento del frente (balcones, carteles publicitarios, eléctricos) se continúa con el de la terraza (jardines, pistas de aterrizaje de aviones $)^{4, "}$.

Algunos de los ejemplos más destacados de la apropiación arquitectónica de las técnicas publicitarias se produjeron tras la Revolución Rusa, en un enorme despliegue propagandístico e ideológico apoyado por el constructivismo. Resulta paradigmático el Pabellón de la URSS para la Exposition des Arts Décoratifs de 1925 , en París, donde Konstantín Mélnikov (1890-1974) despliega una gran pirotecnia publicitaria para el primer pabellón ruso, en una muestra internacional, tras la Revolución de Octubre de $1917^{5}$. Mélnikov saca el máximo partido posible al estrecho solar del que disponía, generando en diagonal una escalera exterior, muy llamativa gracias al juego de paneles de madera que la cubrían, dispuestos alternativamente para generar la sensación de que se desplegaban y se alzaban al paso del visitante. El acceso se remarcaba con un gran emblema de la hoz y el martillo, mientras un poco más abajo, la tipografía repetía esas mismas formas con el nombre de la Unión

\footnotetext{
${ }^{4}$ Moholy-Nagy, László: La nueva visión. Principios básicos del Bauhaus. Buenos Aires: Ediciones Infinito, 2008. p. 97.

${ }^{5}$ Garrido, Ginés: Mélnikov en París, 1925. Barcelona: Fundación Caja de Arquitectos, 2011.
} 
Soviética. El pabellón señalaba su posición dentro de la exposición mediante una torre-hito de estructura metálica y planta triangular, base para el apoyo nuevamente de tipografía.

Durante la década de 1920 se promoverán los proyectos de plataformas para oradores, como por ejemplo la diseñada por Ilya Cháshnik (1902-1929) en 1920, o la Tribuna de Lenin, proyectada por El Lissitzky en 1924; así como las torres de propaganda, como el proyecto de quiosco rotativo para el IV Congreso del Komintern (1922) o el Radio-orador (1922), ambos diseñados por Gustav Klutsis (1895-1942). En estos últimos casos, se trata de estructuras tridimensionales de paneles propagandísticos, donde la tipografía juega un papel destacado.

La reivindicación de la tipografía y los signos gráficos como elementos compositivos autónomos e independientes, se había producido gracias al cubismo, cuando pintores como George Braque (1892-1963) o Pablo Ruiz Picasso (1881-1973) introducen en sus cuadros componentes extrapictóricos, como letras, números o notas musicales, elementos que hasta el momento no formaban parte del lenguaje plástico.

El empleo de la tipografía, no sólo como mero complemento en carteles, rótulos y letreros, sino como parte fundamental de la composición arquitectónica se aprecia claramente en la arquitectura neoplástica. Un ejemplo significativo es el Café De Unie en Róterdam (1924-1925), diseñado por J. J. P. Oud (1890-1963). El uso del color y la tipografía ayudan en la composición de la fachada, y son elementos decisivos en ella tanto como huecos y vanos. Otros proyectos donde la tipografía juega un papel destacado son el Cineac (1933) de Jan Duiker (1890-1935), en Ámsterdam, o la remodelación del cine Vreeburg (1936), de Gerrit Rietveld (18881964), en Utrecht, donde sobresale el monumental rótulo luminoso, principal elemento estructurador de la fachada. Con claras influencias neoplásticas, se puede mencionar, igualmente, el diseño titulado Bildarchitektur II (proyecto de un quiosco), que el húngaro Lajos Kassák (1887-1967) realiza en $1922^{6}$. Se trata de una pieza prismática donde tres muros independientes, y casi autónomos, se individualizan con el tratamiento del color y la tipografía. Esos muros ciegos adquieren el protagonismo del proyecto, convirtiéndose en superficies que pueden acoger todo tipo de propaganda.
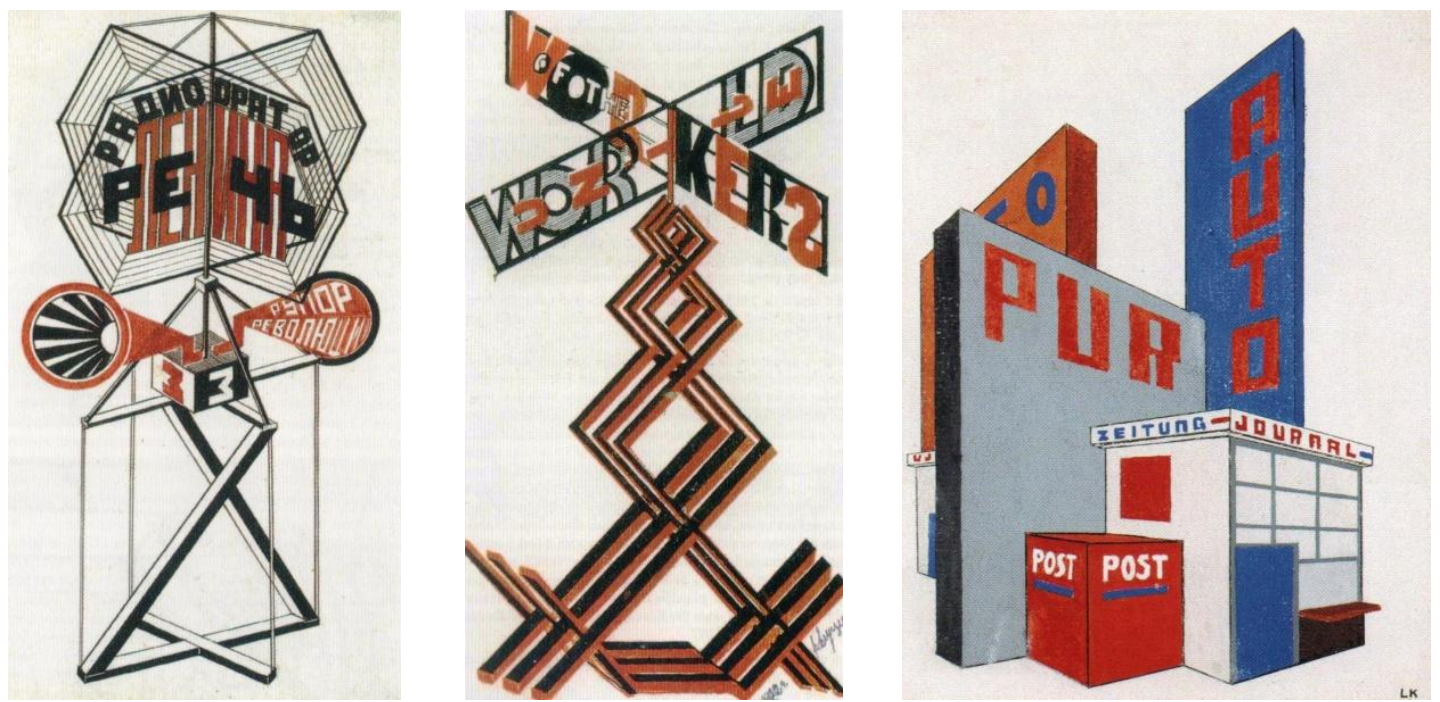

1. Gustav Klutsis: Radio-orador, núm. 3, 1922. 2. Gustav Klutsis: Proyecto del quiosco rotativo de propaganda para el IV Congreso del Komintern, 1922. 3. Lajos Kassák: Bildarchitektur II (proyecto de un quiosco), 1922.

\footnotetext{
${ }^{6}$ VV.AA: Lajos Kassák y la vanguardia húngara. Valencia: IVAM, 1999.
} 
Esta visión panorámica puede ser completada con la Exposición Internacional de Estocolmo, en 1930, donde Erik Gunnar Asplund (1885-1940) mostraba al mundo el triunfo del funcionalismo ${ }^{7}$. La profusión de elementos acristalados aconsejó la instalación de grandes líneas de toldos, que alargaban los voladizos. Sobre estos, grandes letras indicaban la especialización de cada uno de los espacios construidos, guiando a los visitantes en sus recorridos, acompañados, siempre, por banderolas. La magnífica torre-mástil diseñada por Sigurd Lewerentz (1885-1975), ubicada en el pabellón de entrada, puede ser considerada el paradigma de la simbiosis entre arquitectura y publicidad. Un gran número de marcas de patrocinadores se suceden con letras y números de diferente tipografía, acompañadas de un enorme reloj y un par de ojos (que identifican a uno de los anunciantes). La estructura metálica tridimensional que lo sustenta se complementa con una red de cables que arriostran la estructura frente al viento. Su inspiración claramente en el constructivismo ruso, tiene de precedentes ejemplos como el Pabellón de Empresas Cooperativas Dražice (1926-27), de Jiři Kroha (1893-1974); el Pabellón de la U.R.S.S. en la Feria de Comercio de Praga de 1928, de Jaromír Krejcar (1895-1950) ${ }^{8}$; o el proyecto de un Pabellón de exposiciones para el recinto ferial de Budapest (1930), de Alexander Bodon (1906-1993) ${ }^{9}$, que presenta en el frente de acceso una estructura de cinco soportes en celosía, sobre los que se alza un gran cartel publicitario, a la vez que sujetan la marquesina de entrada.

Por último, y tras la crisis del movimiento moderno, la culminación de todo este proceso se lleva a cabo en el pabellón expositivo como pieza icónica en sí mismo, capaz de atraer la atención por su propia imagen, muchas veces desnuda de cualquier otro reclamo o elemento publicitario.

\section{El reclamo publicitario en la obra expositiva de Le Corbusier}

El interés que la publicidad y los medios de comunicación de masas despertaban en Le Corbusier, ha sido puesto de manifiesto en repetidas ocasiones ${ }^{10}$. Las técnicas expositivas y publicitarias de la arquitectura comercial ya llamaban su atención desde sus primeros viajes iniciáticos, recogiendo en sus cuadernos bocetos de escaparates y vitrinas, como por ejemplo las tiendas de la Grabenstraße vienesa, especialmente los almacenes Wiener Werkstätte, obra de Josef Hoffmann (1870-1956), o la galería Knizé, de la que realiza croquis de su fachada ${ }^{11}$.

En sus textos y publicaciones, emplea las imágenes publicitarias, a la manera de ready mades, de una forma similar a las manipulaciones dadaístas ${ }^{12}$. En las páginas, por ejemplo, de la revista $L^{\prime}$ Esprit Nouveau, parodia los recursos explotados por la publicidad comercial, apropiándose de técnicas abstractas y recurriendo a la tipografía ${ }^{13}$, dando como resultado imágenes rotundas de una lógica aplastante.

\footnotetext{
${ }^{7}$ López Peláez, José Manuel: Asplund. Exposición Universal de Estocolmo. Madrid: Rueda, 2004.

${ }^{8}$ VV.AA.: El arte de la vanguardia en Checoslovaquia, 1918-1938. Valencia: IVAM Centro Julio González, 1993.

${ }^{9}$ García, Rafael: Arquitectura moderna en los Países Bajos, 1920-1945. Madrid, Akal, 2010.

10 Por ejemplo, entre otros, Colomina, Beatriz: Privacidad y publicidad. La arquitectura moderna como medio de comunicación de masas. Murcia: CENDEAC - Colegio Oficial de Arquitectos de Murcia - Observatorio del Diseño y la Arquitectura de la Región de Murcia, 2010.

11 Daza, Ricardo: Tras el viaje a Oriente. Charles-Édouard Jeanneret-Le Corbusier. Barcelona: Fundación Caja de Arquitectos, 2015.

${ }^{12}$ Colomina, Beatriz: Doble exposición. Arquitectura a través del arte. Madrid: Ediciones Akal, 2006.

${ }^{13}$ Von Moos, Stanislaus: "Exhibition architect? Otra mirada sobre la 'síntesis' de Le Corbusier". En Calatrava, Juan (Ed.):

Doblando el ángulo recto. Siete ensayos en torno a Le Corbusier. Madrid: Círculo de Bellas Artes, 2009. pp. 43-66.
} 
Dentro de la arquitectura expositiva de Le Corbusier, se pueden identificar algunos hitos importantes en relación al empleo de los recursos publicitarios como elementos de la composición arquitectónica, que se analizan, brevemente, a continuación.

\subsection{El pabellón de L'Esprit Nouveau (1925)}

En su primer enfrentamiento con la arquitectura de exposiciones y pabellones para ferias, el Pabellón de L'Esprit Nouveau para la Exposition des Arts Décoratifs de 1925, en París, Le Corbusier recurre al mejor contenedor que, entiende, puede mostrar las nuevas artes industriales y decorativas, el espacio donde se utilizarán los objetos creados por la técnica moderna: la vivienda. Vinculado a sus propuestas teóricas sobre urbanismo, el pabellón se convierte en una reivindicación del nuevo camino que debe tomar la arquitectura residencial. Lo expuesto es la propia vivienda moderna y su equipamiento. El pabellón, por tanto, no corresponde propiamente a un ejemplo de arquitectura expositiva.

En su interior, es interesante destacar el empleo de recursos museográficos que ayudan a la comprensión del espacio que se está visitando. Un ejemplo sería cómo se indican los recorridos de la visita. Evitando el empleo de cartelería, sobre las propias paredes del pabellón se trazan esquemas en planta del edificio que muestran la composición de espacios, o la diferencia entre interior y exterior. Con la utilización del grafismo, pequeños rótulos y flechas, o la sutil colocación de la alfombra en el suelo, se van remarcando los itinerarios expositivos.

Lo que se muestra en el pabellón es, fundamentalmente, la organización de la vida moderna, rodeados de un mobiliario funcional y acompañados por piezas escogidas de arte contemporáneo. Su ubicación en el espacio recrea la vida real, y evita cualquier recurso expositivo vinculado a los tradicionales museos o salas de exposiciones. No hay vitrinas, pedestales o piezas remarcadas. El mobiliario (como por ejemplo las sillas Thonet) se dispone tal y como debería colocarse para su correcto funcionamiento. Es por esto por lo que, en ocasiones, encontramos fotografías en las que determinadas piezas de mobiliario invaden esa alfombra-itinerario. La alfombra delimita, marca el recorrido y acompaña durante la visita.

Al tratarse de una célula aislada, y no un pabellón propiamente dicho, en el exterior tenía que resolver el aspecto de los cerramientos que formarían las medianerías con las unidades adyacentes. El estudio del color, la delineación de los elementos estructurales conformando paños a la manera de paneles, el grafismo empleado o la ubicación de los accesos introducen las variables necesarias para que el pabellón sea atrayente al público que visita la exposición. El aspecto de vivienda queda reservado al frente donde se ubica el patio cubierto, con la línea de antepecho y la gran cristalera cerrando la sala a doble altura.

El elemento más llamativo se lleva a cabo junto al acceso en planta baja, en un muro lateral, prácticamente ciego, donde se reproducen en perspectiva caballera las iniciales de L'Esprit Nouveau (E N), a partir de cuatro compartimentos de la retícula estructural remarcada en las fachadas. A pesar de la sencilla tipografía, las letras destacan por su gran escala, en un recurso publicitario para promocionar la revista a la que representaba, como si se tratara de una gran portada de la publicación ${ }^{14}$. De manera similar, pero de una forma mucho más espectacular, Alvar Aalto (1898-1976) emplea el mismo recurso, reproduciendo los titulares del periódico en la fachada principal del Turun Sanomat Building (1927-1929), en Turku (Finlandia), para captar la atención de los

\footnotetext{
${ }^{14}$ De hecho, una fotografía coloreada de las iniciales fue utilizada como portada para el número 274 de la revista Casabellacontinuità (abril 1963).
} 
viandantes. La idea ya había sido propuesta anteriormente en el proyecto no ejecutado de los hermanos Vesnin para la sede del periódico Pravda (1924), en Moscú.

Por último, cabe señalar el empleo de las obras artísticas para el reclamo del visitante. En el frente del Pabellón de L'Esprit Nouveau, dando la bienvenida a todos los que se acercaban, se dispuso la escultura Bagneuse (19231925), obra de Jacques Lipchitz (1891-1973). La apuesta por nuevos modelos progresistas para la vida moderna tenía su reflejo, no solamente en la arquitectura y el espacio construido, sino también en la decisión de apoyar un arte nuevo, vanguardista, radicalmente diferente de la tradición. En el interior, junto a las piezas de mobiliario, obras de Fernand Léger (1881-1955), Juan Gris (1887-1927), Amédée Ozenfant (1886-1966), Lipchitz o el propio Le Corbusier, decoraban los espacios.
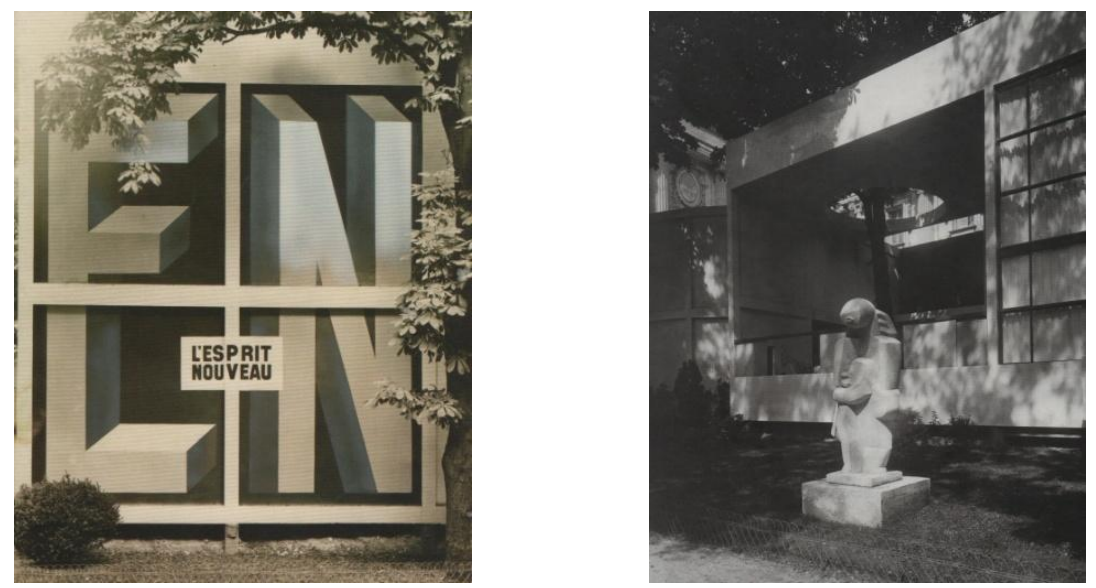

4. Le Corbusier: Pabellón de L’Esprit Nouveau, París, 1925. CFLC-ADAGP. 5. Le Corbusier: Vista del Pabellón de L’Esprit Nouveau, París, 1925. CFLC-ADAGP.

El uso del arte como reclamo tiene su ejemplo más interesante en el Pabellón de la República Española para la Exposición Internacional de París de 1937, obra de Luis Lacasa (1899-1966) y Josep Lluís Sert (1902-1983). Uno de los principales reclamos fueron las obras de arte expuestas no sólo en el interior del pabellón, sino también en su exterior. La apuesta decidida por la modernidad, hizo que se solicitara la colaboración de un grupo magnífico de artistas contemporáneos, muchos vinculados con la escuela de París, y ampliamente reconocidos. La pieza que distinguía el edificio desde lejos, y que se constituía en el hito que daba la bienvenida, era la escultura de Alberto Sánchez (1895-1962) El pueblo español tiene un camino que conduce a una estrella. Junto a ella, obras como Montserrat de Julio González (1876-1942) o Cabeza de mujer de Picasso, recibían al visitante frente a los escalones de acceso. El espacio donde discurría el jardín que separaba el pabellón español del dedicado a Polonia lo ocupaba la Dama oferente, también del pintor malagueño.

Una vez traspasado el umbral, el espacio central bajo el volumen edificado era ocupado por una fuente de mercurio diseñada por Alexander Calder (1898-1976). A la derecha de la entrada, el espacio se cerraba con el Guernica de Picasso, imagen conmovedora que no dejaba indiferente a ninguno de los visitantes, y que se convertiría en el máximo reclamo del pabellón. El ámbito de la rampa era compartido por dos esculturas de Francisco Pérez Mateo (1903-1936): Bañista y Oso. Ya en el interior, la escalera que conducía desde la segunda hasta la primera planta, presentaba el Payés de Joan Miró (1893-1983). El grito desgarrado de Montserrat, las atrocidades reflejadas en el Guernica, la pérdida de la libertad que representaba el Payés, se convertían en mensajes directos y efectivos. Todo un despliegue artístico, de primer orden, que buscaba la legitimación del gobierno republicano y que se ha convertido en un hito de la historia del arte. 
Las obras de arte como piezas de reclamo y captación del interés también son empleadas por Le Corbusier en otra serie de proyectos, aunque con una relevancia mucho menor sobre la composición y estructuración del espacio. Pueden servir de ejemplo, los proyectos del Palais de la Société des Nations (1927), en Ginebra, y el del Centrosoyuz, construido en Moscú entre 1928 y 1936, con la colocación de esculturas de forma clásica sobre grandes columnas, remarcando accesos y puntos significativos; los primeros bocetos para el Ministerio de Educación (1936) de Río de Janeiro, con la presencia significativa de grandes esculturas antropomórficas; y dentro de la arquitectura expositiva, el proyecto de Musées de la Ville et de l'Etat (1935), en París, cuyas fachadas de tratamiento plano contrastan con los grupos escultóricos, que introducen diversos juegos de sombras arrojadas.

En el caso del pabellón para la Exposición Ideal Home (1939), en Arundell Clarke, Londres, los elementos escultóricos aumentan de escala hasta superar el tamaño de la propia pieza expositiva. Una retícula tridimensional, que recuerda estructuras constructivistas, acoge en su interior la representación volumétrica de un gran ojo y una nube, atravesados por los rayos del sol que corona el conjunto. El pabellón, elevado del suelo, parece suspendido del árbol que se dispone detrás. Para acceder hasta él, el visitante tendrá que ascender por una larga rampa. Los ideales del urbanismo moderno se materializan en un juego escultórico de marcado carácter propagandístico, cuyo eslogan (The Radiant City. Sun, space, green) se grafía en el cerramiento de la caja expositiva, reducida al mínimo.

Para su segundo ejemplo de pabellón en una exposición internacional, esta vez para el Pavillon des Temps Nouveaux en París (1937), los mayores recursos expositivos empleados por Le Corbusier se concentraron en el interior. El pabellón en sí no causó el mismo impacto que su precedente de L'Esprit Nouveau, donde contenido y contenedor se confundían en un mismo mensaje. En la nueva propuesta, la arquitectura se había subordinado al contenido. El pabellón era un mero contenedor, de carácter efímero, que protegía la exposición. Todos los esfuerzos de diseño se centraron en los recursos museográficos, el montaje y el contenido. El diseño de un recorrido laberíntico, en forma de bucle, guiaba a los visitantes entre los materiales expuestos. La circulación era continua, creando un espacio fluido a través de rampas, que unían cinco niveles expositivos bajo el contenedor uniforme. Destacaba, principalmente, el empleo de numerosos recursos museográficos. Con la ayuda de paneles, pinturas murales, esquemas, maquetas, dioramas, fotografías y fotomontajes, en el interior se exponían todos los temas que Le Corbusier y los CIAM habían estado desarrollando.
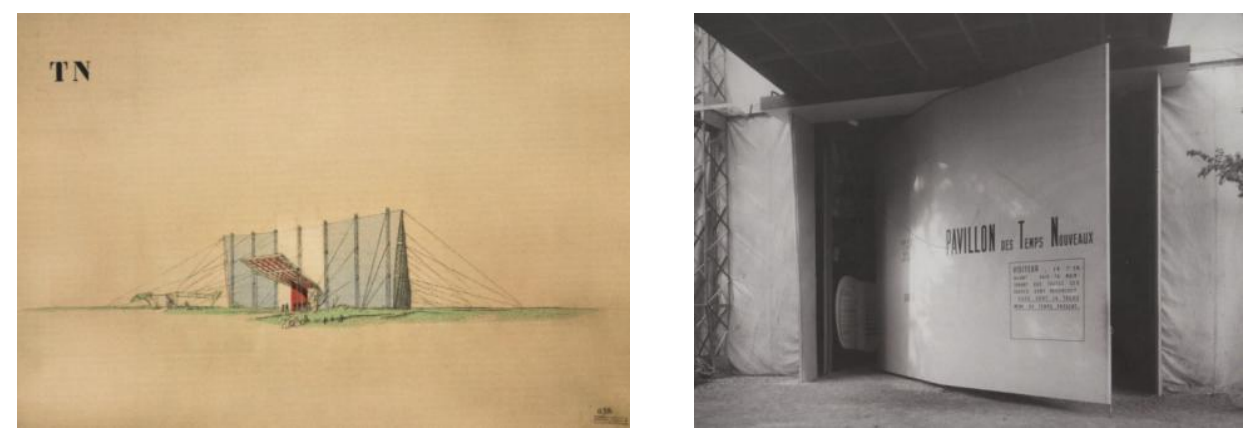

6. Le Corbusier, Pavillon des Temps Nouveaux, perspectiva, 1937. FLC 658 OFLC-ADAGP. 7. Le Corbusier, Pavillon des Temps Nouveaux, puerta pivotante, 1937. OFLC-ADAGP. 
La imagen exterior del pabellón presentaba las características de una tienda. Para su construcción se utilizó un sistema de estructura metálica, tirantes, cables y tensores, recubriendo todo el esqueleto con lonas. En uno de los diseños, se muestra un estudio de color, diferenciando tonos blancos y azulados para la envolvente, mientras que la puerta de entrada, remarcada por una gran marquesina, aparecía pintada en rojo. El tono vivo de este color hacía de reclamo para el visitante, que identificaba fácilmente el lugar de acceso. La puerta pivotante de eje central diferenciaba la entrada y la salida. Esta puerta, con su gran dimensión se convierte a la vez en un recurso expositivo, puesto que se transforma en una superficie más donde exponer o donde grafiar.

\subsection{Pabellón Nestlé (1928)}

Uno de los mejores ejemplos donde puede apreciarse el despliegue publicitario dentro de la arquitectura expositiva de Le Corbusier es el Pabellón Nestlé, un stand promocional de esa gran sociedad comercial. El encargo solicitaba la realización de un pequeño pabellón de exposiciones, que fuera desmontable y fácil de transportar, puesto que la intención era que fuese reutilizado en las ferias de París (1928), Burdeos (1929) y Marsella (1930), aunque, finalmente, sólo se montó en la primera de ellas.

El pabellón se resolvió mediante una estructura metálica recubierta de paneles de vidrio y de madera sobre los que se aplicaba un original diseño gráfico, respetando la imagen de la marca comercial, pero fuertemente influido por la estética desarrollada en la revista L'Esprit Nouveau.

La cubierta inclinada se resolvió a dos aguas, con su recogida hacia el interior y evacuando a través de dos tubos metálicos colocados en ambos extremos, simulando formar parte de la estructura del pabellón. Formalmente, supone el antecedente de las cubiertas tipo paraguas que Le Corbusier desarrollará en versiones de pabellones posteriores como los de la Exposición de Lieja (1939), el Pavillon Synthèse des Arts Majeurs (en Porte Maillot, 1950), o el Palacio de exposiciones de Estocolmo (1962), y que conducirán a la solución definitiva de la Maison de l'Homme o Pabellón de Zúrich (1963-1967).

Exteriormente, Le Corbusier recurrió al empleo de dos banderas, una en cada extremo, como dispositivos para captar la mirada. Los mástiles son elementos verticales que contrastan con el volumen edificado como una pieza longitudinal. Se convierten en ejes que fijan el edificio al lugar, lo señalan y lo identifican en la distancia. La bandera, agitada por el viento, es una forma dinámica, cambiante, que introduce destellos de color en su continuo movimiento. Podemos encontrar otros ejemplos de la utilización de mástiles y banderas en la arquitectura del maestro, como en el Pabellón de la Aviación S.T.A.R. (1930), en Le Bourget, donde la estructura del mástil con la ayuda de unos cables, sujeta la marquesina que remarca el acceso al interior. En otros casos, su uso no se haya necesariamente vinculado a los espacios expositivos, como por ejemplo en el testero de los Immeubles-Villas (1922), o como en el caso del Centrosoyuz, acorde con la imagen del edificio debido a su carácter representativo.

La imagen exterior del Pabellón Nestlé se hizo más llamativa con la inclusión de enormes reproducciones de botes de cacao, logotipos y marcas comerciales, realizados en llamativos colores, que contrastaban con el azul pálido aplicado a los cerramientos exteriores. Esta idea publicitaria sería ampliamente utilizada a partir de los años 50 en todo tipo de ferias, como por ejemplo en el Castello pubblicitario Pirelli, realizado por Luigi Gargantini en $1951^{15}$, donde el pabellón ha desaparecido, para dejar lugar, únicamente, al carácter publicitario de pancartas, paneles, logotipos, cajas y piezas llamativas, llevado hasta un punto extremo, casi de paroxismo.

\footnotetext{
${ }^{15}$ Publicado, por ejemplo en el número 260 de la revista Domus (julio-agosto 1951).
} 

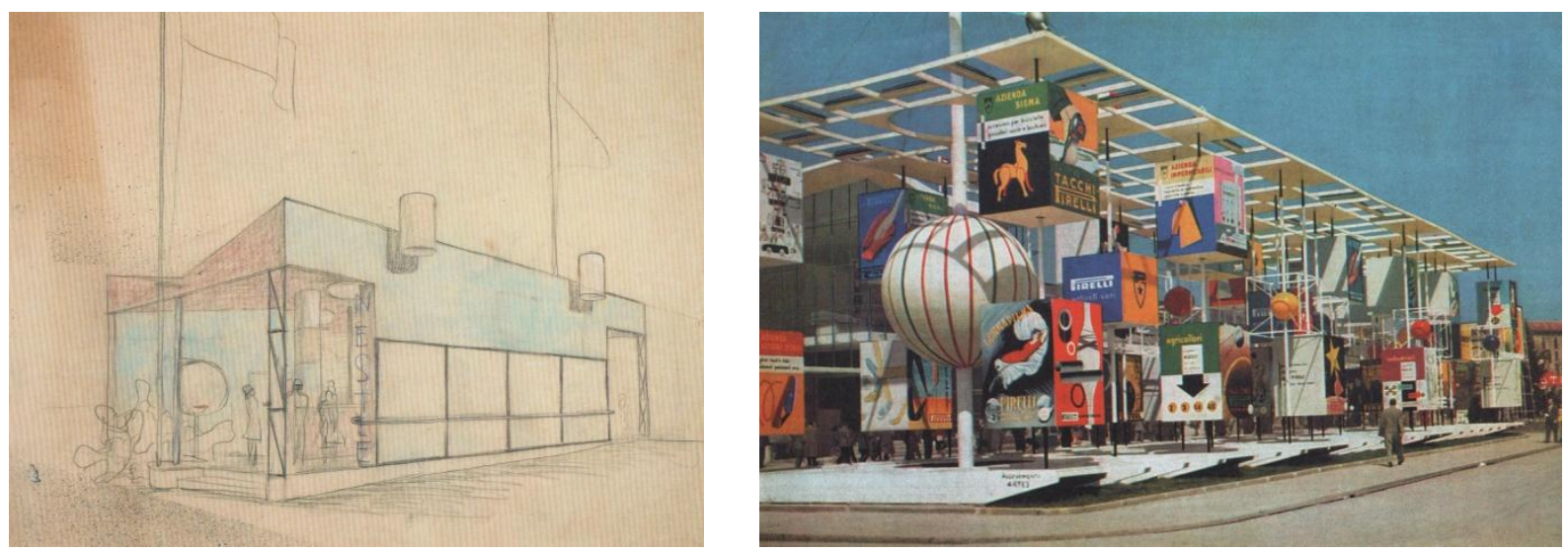

8. Le Corbusier, Pabellón Nestlé, perspectiva, 1928. FLC 18092 OFLC-ADAGP. 9. Luigi Gargantini, Castello pubblicitario Pirelli, 1951.

En el Pabellón Nestlé se diferencian, claramente, dos funciones. La parte frontal del edificio, correspondiente a la fachada principal, se formula como punto de venta de los productos de la marca comercial. La parte inferior del cerramiento se construye en vidrio para mostrar la gama de productos, como si se tratara de expositores. En el lado opuesto un mostrador, a todo lo largo del pabellón, permite su compra.

Un pasamanos continuo recorre el cerramiento, tanto por el interior como por el exterior, dando la sensación de que los productos están expuestos para contemplarlos por ambos lados. Cuando se recorren los escaparates desde fuera, la barandilla te invita a continuar curioseando en el interior. Acompañando el recorrido lineal, de una sola dirección, se encuentra la bancada que conforma el espacio de atención a los compradores. El mostrador repite el mismo tipo de pasamanos, delimitando perfectamente el flujo de visitantes.
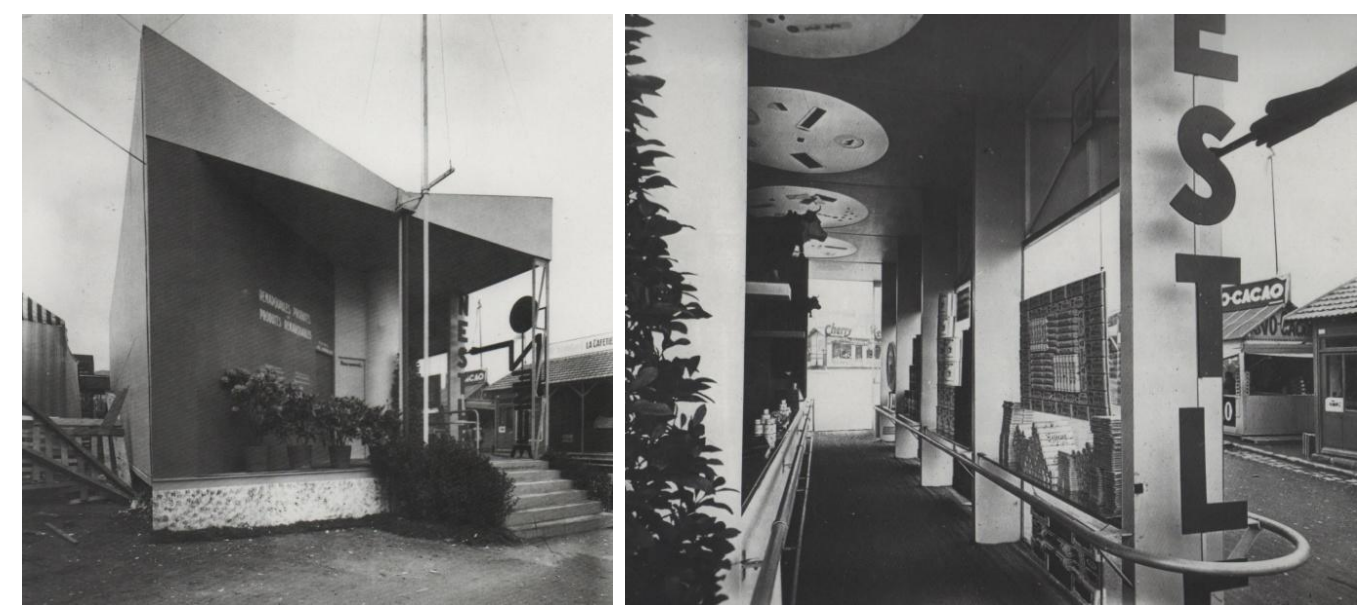

10. Le Corbusier, Pabellón Nestlé, lateral, 1928. OFLC-ADAGP. 11. Le Corbusier, interior del Pabellón Nestlé, detalle del pasamanos, 1928. OFLC-ADAGP.

En la tienda Mortimer Gall Electrical Centre (1936), ubicada en la Cannon Street de Londres, Walter Gropius (1883-1969) y Maxwell Fry (1899-1987), utilizaron un motivo parecido al curvar la esquina de su escaparate, facilitando con ello el movimiento hacia la puerta del establecimiento, situada lateralmente. En un nivel superior, el nombre de la tienda se lee siguiendo ese mismo movimiento que acaba sobre la entrada del local. 
La parte posterior del pabellón Nestlé se dedica a una función puramente expositiva, donde se daba a conocer la marca comercial, su historia y los productos que ofrecía. El espacio monótono que produciría una sala rectangular es fuertemente modificado con la inclusión del cuerpo triangular que conforma la trasera del mostrador de ventas. El lado opuesto, rectilíneo, es ocupado por los expositores. El espacio intermedio es el que acoge a los visitantes. Nuevamente, un esquema lineal en una sola dirección ordena el recorrido.

En ambos extremos del volumen del pabellón se diferencian tres accesos-salidas. El primero corresponde a los compradores del punto de venta, el intermedio al acceso de personal (que conduce al espacio tras el mostrador), y el último es el utilizado por el visitante de la exposición. El desnivel de la calle imposibilitó el acceso a cota cero por ambos extremos, obligando a la colocación de unos escalones para salvar la diferencia entre entrada y salida.

El carácter simétrico de la composición sólo se rompe con la colocación, en vertical, del nombre de la marca comercial. Su posición en el extremo izquierdo del pabellón indica al visitante el punto por donde puede acceder al interior (materializado incluso con un círculo sobre los signos gráficos). Las letras, independizadas de carteles o paneles de apoyo, se muestran como piezas exentas, pintadas en un contrastante tono anaranjado. Sobre ellas, destaca la letra $\mathrm{N}$, de mayor tamaño, cuyo brazo derecho se quiebra para señalar amablemente, como si de un brazo y una mano se tratara, el lugar de acceso al local y el recorrido recomendado.

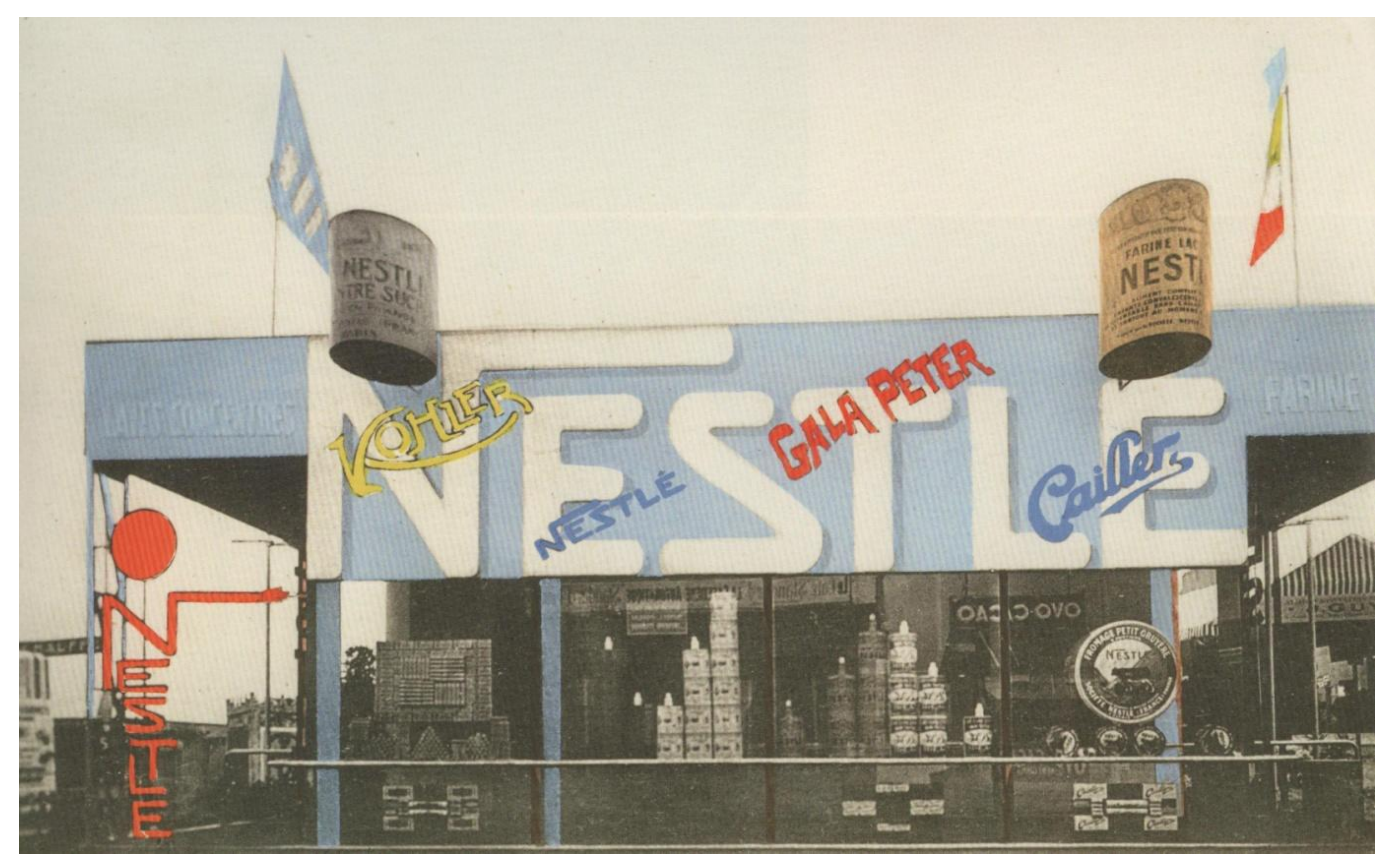

12. Le Corbusier, Pabellón Nestlé, 1928. CFLC-ADAGP.

\subsection{Pabellón Bat'a (1937)}

La empresa, de origen checo, Bat'a se había ganado un gran prestigio internacional por su dinámica, su carácter innovador y sus productos, realizando desde zapatos a aviones. Jean Bat'a, el director de la empresa tenía contactos con Le Corbusier desde 1932, y el arquitecto había preparado un estudio sobre tiendas de la marca en 1936, principalmente zapaterías. 
Los diseños para las Boutiques Bat'a, adaptados a diferentes dimensiones de locales, muestran una composición elegante y sobria en fachadas, generalmente simétricas, donde los elementos publicitarios han sido reducidos al mínimo. Centrado, y sobre la zona de escaparates, se disponía un rótulo identificando la marca comercial. La fachada, resuelta en profundidad, permitía concretar un espacio intermedio entre el tránsito de la calle y el interior cerrado de la boutique. En ese lugar, los clientes podían contemplar con tranquilidad los productos colocados en expositores dispuestos en el perímetro o, en otros casos, exentos en el centro del espacio.

Para la Exposición Internacional de París de 1937, la empresa sólo pudo obtener un solar de $130 \mathrm{~m}^{2}$, donde poder construir un pequeño pabellón, que finalmente no llegó a realizarse. La pieza propuesta por Le Corbusier consistía en un paralelepípedo casi cúbico por sus proporciones, 13'50×11×12 metros, resuelto mediante una estructura de pilares de acero, compuestos por perfiles en doble $\mathrm{T}$.

Considerando que el lugar no permitía crear grandes alardes arquitectónicos en su exterior, Le Corbusier centró todo su interés en el interior del pabellón. Nuevamente, sólo se recurre al empleo de la tipografía para generar el nombre de la marca, en una composición de fachada, esta vez claramente asimétrica. El espacio interior, por el contrario, se hallaría recubierto de paneles luminosos y tiras fotográficas. Los paneles de vidrio mate se encontrarían decorados, como sucedía, por ejemplo, en el techo donde se representaba el planisferio. Con un ingenioso sistema, sobre parte de estos paneles se proyectarían anuncios publicitarios de la marca.

De los plafones del techo se suspendería un avión modelo ZLIN XII, fabricado por la propia empresa. Este recurso también lo planteó, en la misma exposición para el Pavillon des Temps Nouveaux. En ese caso, la maqueta de un avión introducía la comparación entre el urbanismo moderno (con ejemplos expuestos a lo largo de todo el montaje) y una ciencia de precisión como es la aeronáutica. Le Corbusier nos estaba diciendo que la vivienda debía ser una machine à habiter. En el caso del Pabellón Bat'a, el avión suspendido del techo quería demostrar la diversidad de productos que la firma, originariamente dedicada a la venta de calzado, había llegado a comercializar, en una muestra clara de su apuesta por la modernidad.

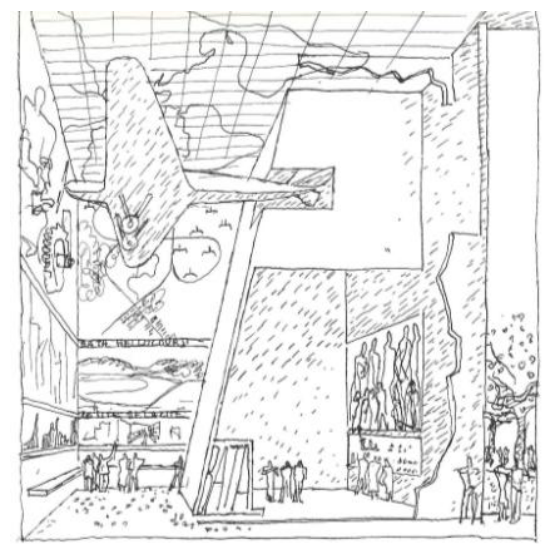

13. Le Corbusier, Pabellón Bat'a, perspectiva del interior, 1937. FLC 17814 @FLC-ADAGP.

El pabellón no llegó a construirse debido a las malas relaciones que surgieron entre Jean Bat'a y Le Corbusier, a causa, principalmente, de un malentendido en cuestión de honorarios. Finalmente, el encargo fue llevado a cabo por otro arquitecto. La propuesta de Le Corbusier resolvía el espacio expositivo en una única planta. El espacio se generaba alrededor de unas cabinas centrales, dedicadas a la pedicura, que ordenaban un recorrido abierto y fluido. El sistema de accesos, no diferenciado, se resolvía con una entrada y una salida, localizadas en distintas fachadas. 
La iluminación natural era, únicamente, cenital, y entraba filtrada a través de los paneles de vidrio que componían el techo. La iluminación artificial se resolvía en tres niveles distintos. Un primer nivel correspondía a la iluminación aportada por las vitrinas y expositores de las zonas bajas del pabellón. La segunda fuente de iluminación artificial era generada por los paneles luminosos colocados en la parte intermedia de las paredes. Por último, en la parte superior del edificio, se habían colocado unas líneas de neones, como iluminación de apoyo.

Como puede apreciarse en las secciones y la perspectiva interior, los recursos expositivos jugaban un papel fundamental en la percepción espacial del interior. El espacio se subdividía en tramos y franjas, por la colocación de paneles de cerramiento que, o no llegaban al suelo, o no llegaban al techo. Sobre todo el espacio, los plafones decorados con el planisferio unificaban el espacio, que era sobrevolado por el modelo de avión suspendido. Sobre casi un cuarto de este techo, y en una especie de cámara oscura, se programaban proyecciones publicitarias.

El cerramiento lateral era completamente ciego, acogiendo en toda su superficie los paneles expositivos. Estos se disponían en bandas horizontales que iban ganando en anchura conforme se iba subiendo en altura. Cuanto más alejada se encontraba la información del visitante, mayor dimensión se daba a los paneles, y por tanto, a lo representado. De manera similar al montaje expositivo planteado en los stands interiores del Pavillon des Temps Nouveaux, todos los cerramientos eran invadidos por lo expuesto, todas las superficies eran ocupadas. Como si de un avión de guerra se tratara, los visitantes eran bombardeados por la publicidad de Bat'a.

\section{Procedencia de las imágenes}

Imagen 1. CC-0427/G. Klutsis/C377-73. State Museum of Contemporary Art. Costakis Collection. Tesalónica. Imagen 2. CC-0386/G. Klutsis/C978-747. State Museum of Contemporary Art. Costakis Collection. Tesalónica. Imagen 3. Kassák Museum. Budapest.

Imagen 4. OFLC-ADAGP.

Imagen 5. OFLC-ADAGP.

Imagen 6. FLC 658 OFLC-ADAGP.

Imagen 7. OFLC-ADAGP.

Imagen 8. FLC 18092 OFLC-ADAGP.

Imagen 9. Domus, julio-agosto 1951, número 260.

Imagen 10. OFLC-ADAGP.

Imagen 11. OFLC-ADAGP.

Imagen 12. OFLC-ADAGP.

Imagen 13.FLC 17814. OFLC-ADAGP.

\section{Bibliografía}

Para obtener una visión panorámica de las principales obras, la evolución en los proyectos e ideas sobre la arquitectura expositiva de Le Corbusier, puede servir de referencia la siguiente bibliografía mínima (prescindiendo de monografías generalistas y estudios de edificios individuales):

Boralevi, Alberto: "The architectural conception of the museum in the work of Le Corbusier". En Museum Management and Curatorship, 1983, vol. 2, 2, pp. 177-189. 
Herschdorfer, Nathalie; Umstätter, Lada (Eds.): Le Corbusier and the power of Photography. Londres: Thames \& Hudson Ltd., 2012.

Mory, Pascal: "Le Corbusier and the syndrome of the museum". En Ahrenberg, Staffan; Cohen, Jean-Louis (Eds.): Le Corbusier's secret laboratory. From Painting to Architecture. Estocolmo: Hatje Cantz, 2013. pp. 257273.

Moulis, Antony: "Le Corbusier, the museum projects and the spiral figured plan". En Takhar, Jaspreet (Ed.): Celebrating Chandigarh. Ahmedabad: Mapin, 2002. pp. 348-357.

Navarro Segura, María Isabel: Le Corbusier expone. Las Palmas de Gran Canaria: Centro Atlántico de Arte Moderno, 2011.

O'Byrne Orozco, María Cecilia: Espirales, laberintos, molinetes y esvasticas en los museos de Le Corbusier, 1928-1939. Bogota: Universidad de los Andes-Ediciones Uniandes, 2011.

VV.AA.: Le Corbusier expose. Milán: Silvana Editoriale, 2011. 